\title{
Lossy-Transmission-Line Analysis of Frequency Reconfigurable Rectangular-Ring Microstrip Antenna
}

\author{
Bambang Setia Nugroho, Fitri Yuli Zulkifli, and Eko Tjipto Rahardjo \\ Department of Electrical Engineering, Universitas Indonesia, Kampus Baru UI, Depok, West Java 16424, Indonesia \\ Correspondence should be addressed to Bambang Setia Nugroho; bambang.setia@ui.ac.id
}

Received 12 August 2014; Accepted 17 October 2014; Published 13 November 2014

Academic Editor: Xianming Qing

Copyright (C) 2014 Bambang Setia Nugroho et al. This is an open access article distributed under the Creative Commons Attribution License, which permits unrestricted use, distribution, and reproduction in any medium, provided the original work is properly cited.

\begin{abstract}
An analytical model for a frequency reconfigurable rectangular-ring microstrip antenna is proposed. The resonant frequencies and input impedance of the reconfigurable antenna are analyzed using a lossy-transmission-line (LTL) model. By making use of $Y$ admittance matrices, a formulation for the input impedance is analytically derived. The structure of the frequency reconfigurable antenna consists of a rectangular-ring shaped microstrip antenna which is loaded with a rectangular patch in the middle of the rectangular-ring antenna and fed by a microstrip line. RF switches are applied to connect the load to the antenna in order to reconfigure the operating frequencies. By modeling the antenna into a multiport equivalent circuit, the total input impedance is analytically derived to predict the resonant frequencies. To verify the analysis, the model input impedance and reflection coefficient calculation have been compared with the full-wave simulation and measurement results. The proposed model shows good agreement with full-wave simulated and measured results in the range of $1-3 \mathrm{GHz}$.
\end{abstract}

\section{Introduction}

Frequency reconfigurable antennas are receiving higher attention in line with the development of advanced communications system. Different techniques have been presented to achieve reconfigurability of the antenna operating frequencies, but mostly the reconfigurability is controlled by means of RF switches, such as PIN diodes, FETs, varactor diodes, and RF-MEMS switches [1]. Recently, with the urge to integrate various types of wireless communication systems such as UMTS, LTE, WiFi, and WiMAX into a single device, the need for novel multiband frequency reconfigurable antenna is even more important.

A lot of reconfigurable antenna structures have been widely reported, such as slot $[2-4]$, monopole $[5,6]$, squarering [7-9], and rectangular-ring antenna [10-12]. However, there are only few design procedures or theories of operation for the reconfigurable antennas that allow designers to create their own antennas using the same principles. The reconfigurable antennas are commonly designed and characterized using full-wave solver. Reconfigurable slot antenna in [4] was one that has been discussed in detail covering analytical model using transverse resonant technique, full-wave characterization, and design procedure, whilst square/rectangularring shaped reconfigurable antennas in [7-12] have reported the full-wave characterization and experimental validation but did not include the analytical model representation.

Transmission line model (TLM) is commonly used to predict the input characteristics of a microstrip antenna due to its accuracy and numerical efficiency, whilst lossy transmission line (LTL) model can be utilized for modeling a lossy structure. The use of the LTL model on a loaded squarering antenna has been introduced by Garg and Reddy [13]. Garg derived the input characteristics of a nonreconfigurable square-ring microstrip antenna which loaded with a single stub. However, applying the LTL model to represent a reconfigurable antenna has not been attempted.

Therefore, in this paper, we extend the use of the LTL model and combine it with multiport network analysis to create a general model equation for the reconfigurable antenna previously reported in [10-12]. The model could be used to explain more detail on the effect of the switch position 


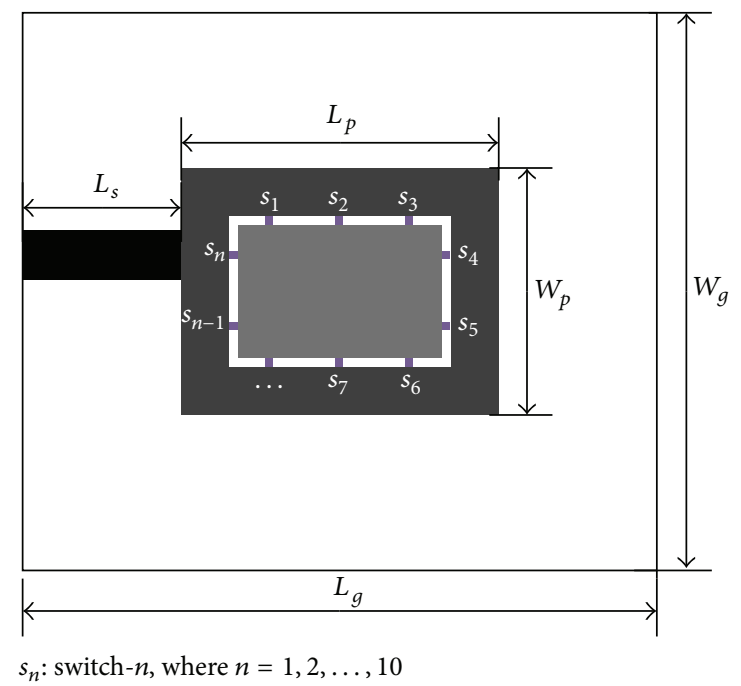

FIGURE 1: Geometry of the frequency reconfigurable antenna.

on the antenna's resonant frequency. Furthermore, this paper also describes an analytical derivation of the input impedance and prediction of the frequency alteration due to the change in switch combinations.

\section{The Antenna Structure}

The basic antenna structure has been introduced in [1012]. In this paper, we modify the antenna into a general form with $n$ number of switches as shown in Figure 1 . The antenna was designed with a rectangular-ring shaped and fabricated on an FR4 substrate with a thickness of $1.6 \mathrm{~mm}$, permittivity of 4.4 , and loss tangent of 0.02 . The dimension of the rectangular-ring antenna is $34.2 \mathrm{~mm}\left(W_{p}\right) \times 44 \mathrm{~mm}$ $\left(L_{p}\right)$, and the width of the ring is $6.7 \mathrm{~mm}$. The antenna is fed by microstrip line with the length of $22 \mathrm{~mm}\left(L_{s}\right)$ and the width of $6.8 \mathrm{~mm}$. The antenna is loaded with a rectangular patch which is positioned in the middle of the ring with dimension of $28.2 \mathrm{~mm} \times 18.4 \mathrm{~mm}$. The placement of the load into the rectangular ring creates a rectangular ring slot of $1.2 \mathrm{~mm}$ width. The $n$-number RF switches are placed into the slot to connect the load to the antenna. The switches are placed arbitrarily on each side of the rectangular slot. By changing the position of the load connected to the antenna using different $\mathrm{ON}$-switch combination, different frequency bands can be produced.

\section{The Proposed Model Representation}

3.1. Proposed Equivalent Circuit. In this section, we propose an analytical model for the reconfigurable rectangular-ring microstrip antenna. The antenna is simplified into an equivalent circuit and the total input impedance is analytically derived to predict the reflection coefficient over a certain frequency range.

The proposed multiport equivalent circuit model of the reconfigurable antenna is shown in Figure 2. The model is built using the following rules: (1) the rectangular ring is modeled as a parallel combination of several transmission line sections; (2) the RF switches locations are represented as ports. When the switch is OFF, the port is modeled as an open circuit port or load admittance $\left(Y_{l n}\right)=0$, and when a switch is $\mathrm{ON}$, then the associated port model is terminated by a load admittance $Y_{L n}$; (3) as shown in Figure 2, the position of port $n$ coincides with the port 0 . When $s_{n}$ is OFF the port will be open circuit and the voltage of port $n, V_{n}$, will be equal to the voltage of port $0, V_{0}$. Otherwise, when $s_{n}$ is $\mathrm{ON}$, the port will be terminated by load admittance, $Y_{L n}$. Hence, when two port locations coincide, the ports will exhibit the same behavior as a single port. So, only one port is taken into account in the model equation.

The admittance matrix approach is most suitable for the analysis of the equivalent circuit. The general model equation for the reconfigurable antenna with $n$-switches is described as

$$
\left[\begin{array}{c}
I_{0} \\
I_{1} \\
\vdots \\
I_{n}
\end{array}\right]=\left[\begin{array}{cccc}
Y_{00} & Y_{01} & \cdots & Y_{0 n} \\
Y_{10} & Y_{11} & \cdots & Y_{1 n} \\
\vdots & \vdots & \ddots & \vdots \\
Y_{n 0} & Y_{n 1} & \cdots & Y_{n n}
\end{array}\right]\left[\begin{array}{c}
V_{0} \\
V_{1} \\
\vdots \\
V_{n}
\end{array}\right] .
$$

The above equation can be used for arbitrary number of switches applied to the antenna.

The port current, $I_{n}$, is derived as

$$
I_{n}=Y_{L n} V_{n} .
$$

The input impedance of the rectangular-ring antenna, $Z_{A}$, as shown in Figure 2 is obtained by solving this relationship,

$$
Z_{A}=\frac{V_{0}}{I_{0}} .
$$

Then, the input impedance observed from the microstrip feeder line, $Z_{\text {in }}$, as depicted in Figure 2 is

$$
Z_{\text {in }}=Z_{c f} \frac{Z_{A}+Z_{c f} \tanh \gamma_{f} L_{f}}{Z_{c f}+Z_{A} \tanh \gamma_{f} L_{f}},
$$




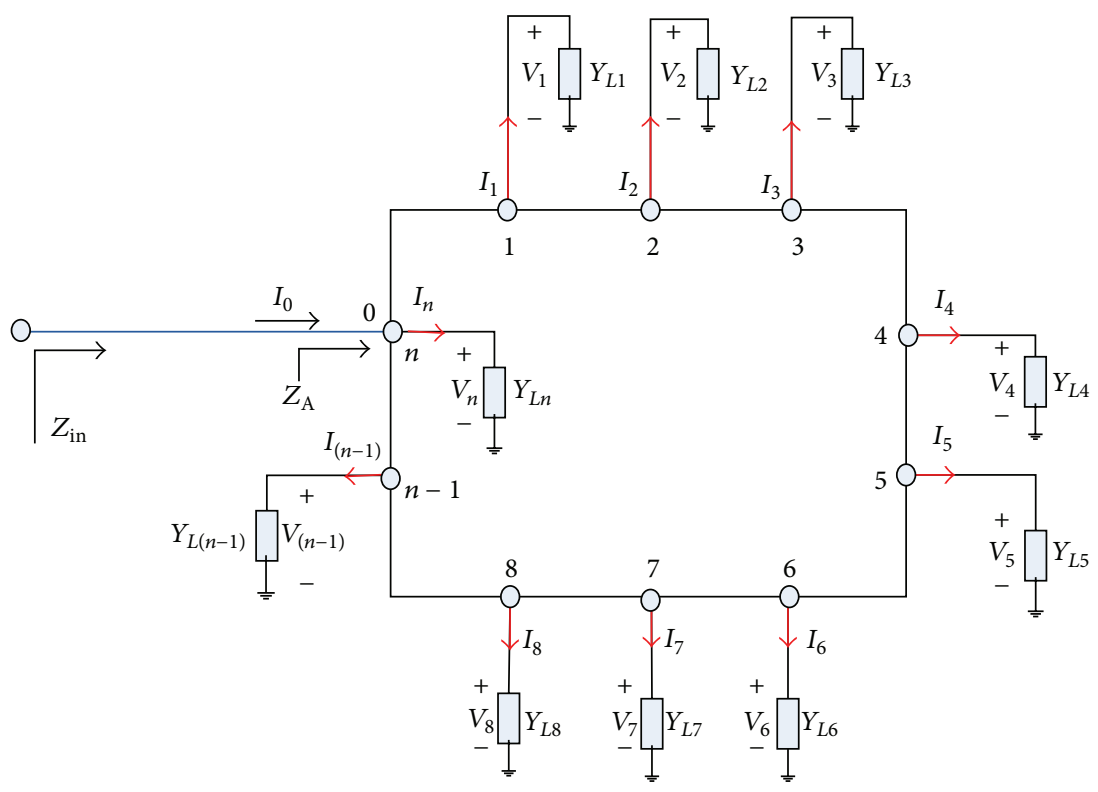

FIGURE 2: Proposed multiport transmission line equivalent circuit of frequency reconfigurable rectangular-ring microstrip antenna.

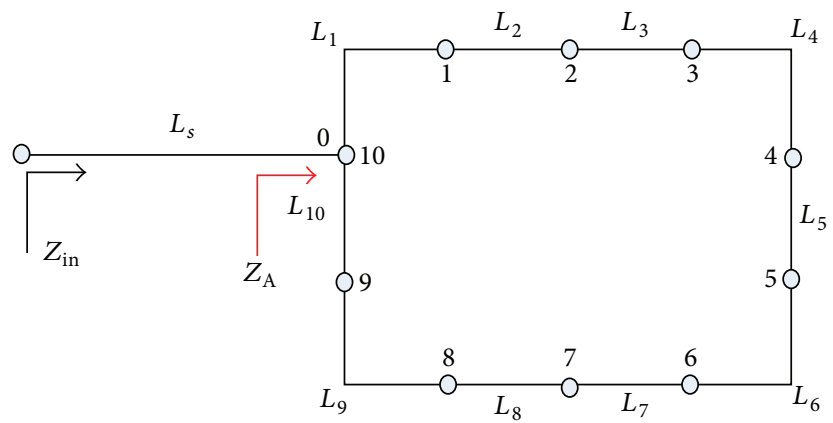

FIGURE 3: Definition of transmission line section length, $L_{n}$, input impedance of the rectangular-ring antenna, $Z_{A}$, and the input impedance observed from the microstrip feeder line, $Z_{\text {in }}$.

where $Z_{c f}$ is a characteristic impedance of line feeder, $\gamma_{f}$ is propagation constant of feeder line, and $L_{f}$ is feeder line length.

In the case of the reconfigurable antenna with ten RF switches as reported in [10-12], $n$ in (1) equals to $0,1,2, \ldots 9$. The port 10 is not taken into account because its location coincides with port 0 . The ports are open circuit when the switch is OFF and when the switch is ON, the port current will be equal to

$$
I_{n}= \begin{cases}Y_{L 10} V_{0}, & \text { for } n=0, \\ Y_{L n} V_{n}, & \text { for } n=1,2, \ldots, 9\end{cases}
$$

In the following subsections, the derivation of the matrix components and other parameters are conducted in the case of the reconfigurable antenna with $10 \mathrm{RF}$ switches.

3.2. Determining Y-Matrix Components $\left(Y_{n m}\right)$ and Transmission Line Parameters. As seen in Figure 3, we defined the length of the line section between the port $(n-1)$ and the port and by $L_{n}$, for example, $L_{1}$ is a line section of port 0 to port 1.

The $Y$-admittance matrix components, $Y_{n m}$, can be derived by using this following rule [14]:

$$
Y_{n m}=\left.\frac{I_{n}}{V_{m}}\right|_{V_{k}=0, \text { for } k \neq m} .
$$

3.2.1. Determining $Y_{00}$. To determine $Y_{00}$, all of the ports except port 0 are short circuited as shown in Figure 4. Therefore, using the transmission (ABCD) matrix [14] for each line section $L_{1}$ and $L_{10}$, the admittance component $Y_{00}$ can be obtained,

$$
\begin{gathered}
\left(\begin{array}{c}
V_{0} \\
I_{0}^{\prime}
\end{array}\right)=\left(\begin{array}{cc}
\cosh \gamma_{r} L_{1} & Z_{c r} \sinh \gamma_{r} L_{1} \\
\frac{1}{Z_{c r}} \sinh \gamma_{r} L_{1} & \cosh \gamma_{r} L_{1}
\end{array}\right)\left(\begin{array}{c}
0 \\
I_{1}
\end{array}\right), \\
Y_{00}^{\prime}=\frac{I_{0}^{\prime}}{V_{0}}=\frac{\cosh \gamma_{r} L_{1}}{Z_{c r} \sinh \gamma_{r} L_{1}}=Y_{c r} \operatorname{coth} \gamma_{r} L_{1} .
\end{gathered}
$$




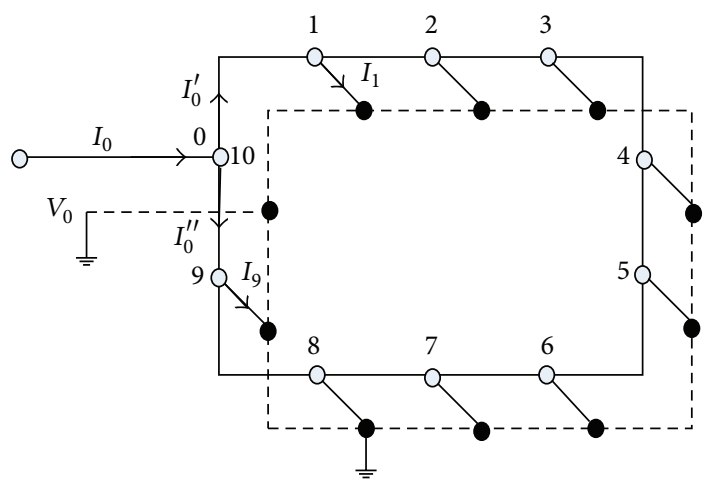

FIGURE 4: Equivalent circuit for determining $Y_{00}$ where all of the ports except port 0 are short circuited.

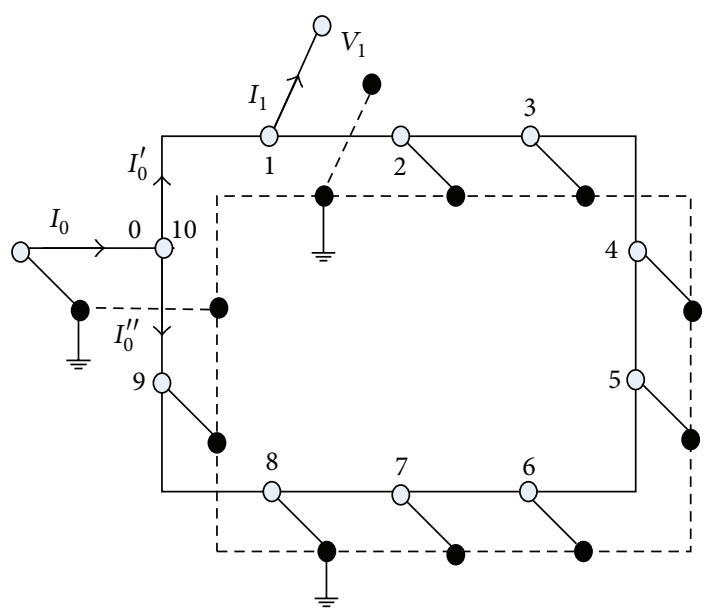

FIGURE 5: Equivalent circuit for determining $Y_{01}$ where all of the ports except port 1 are short circuited.

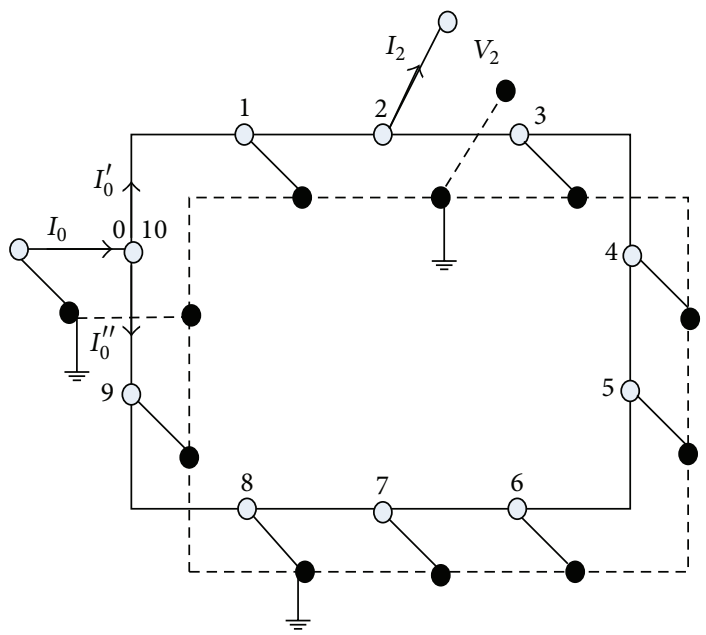

FIGURE 6: Equivalent circuit for determining $Y_{02}$ where all of the ports except port 2 are short circuited.

The admittance $Y_{00}^{\prime \prime}$ is determined using the same method in (7). The admittance matrix component $Y_{00}$ equals $Y_{00}^{\prime}+Y_{00}^{\prime \prime}$ and it is defined as

$$
Y_{00}=Y_{c r}\left(\operatorname{coth} \gamma_{r} L_{1}+\operatorname{coth} \gamma_{r} L_{10}\right) \text {. }
$$

Whereas $Y_{c r}$ is characteristic admittance of the ring antenna $=1 / Z_{c r}, \gamma_{r}$ is propagation constant of ring antenna, and $L_{1}, L_{10}$ are line section length of port 0 to port 1 and port 9 to port 0 , respectively.

3.2.2. Determining $Y_{01}$. To determine $Y_{01}$, all of the ports except port 1 are short circuited as depicted in Figure 5. Therefore, admittance $Y_{01}$ can be defined using transmission matrix equation in each transmission line section $L_{1}$ and $L_{10}$ 


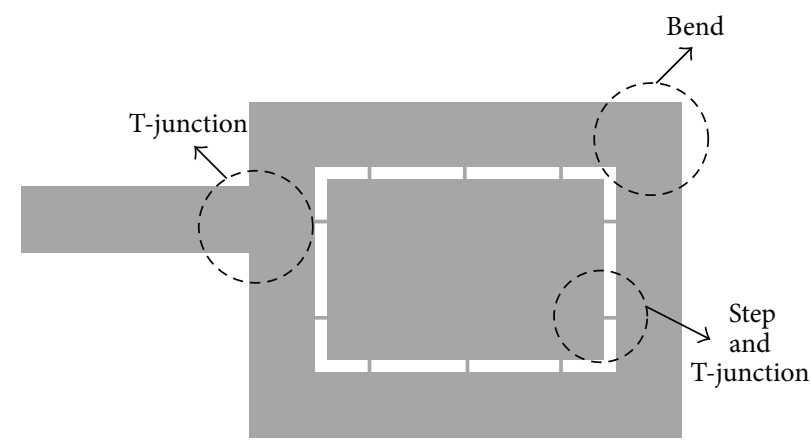

FIGURE 7: Various discontinuities in the reconfigurable antenna.

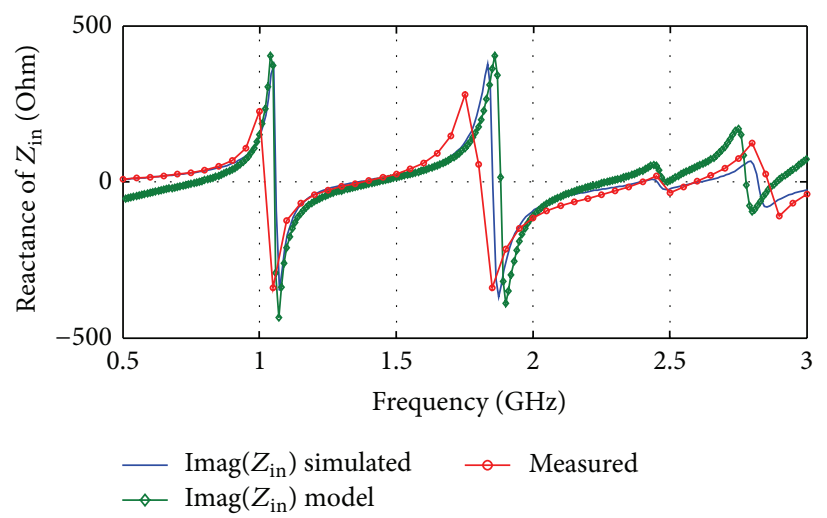

(a)

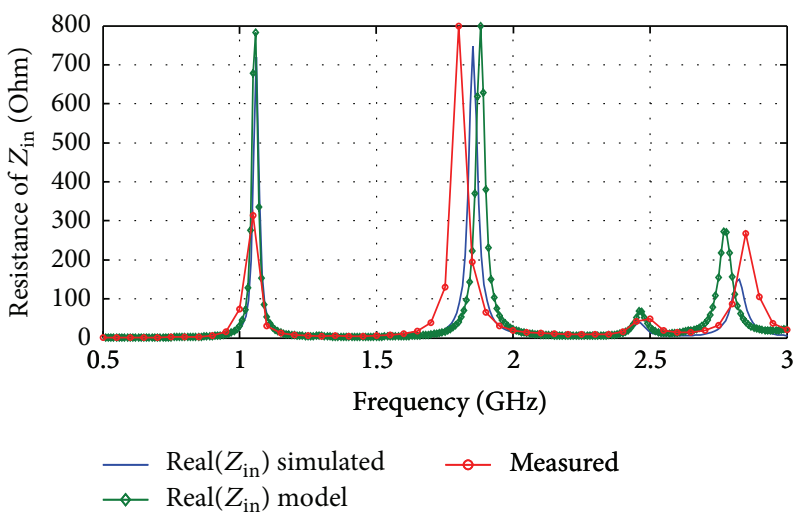

(b)

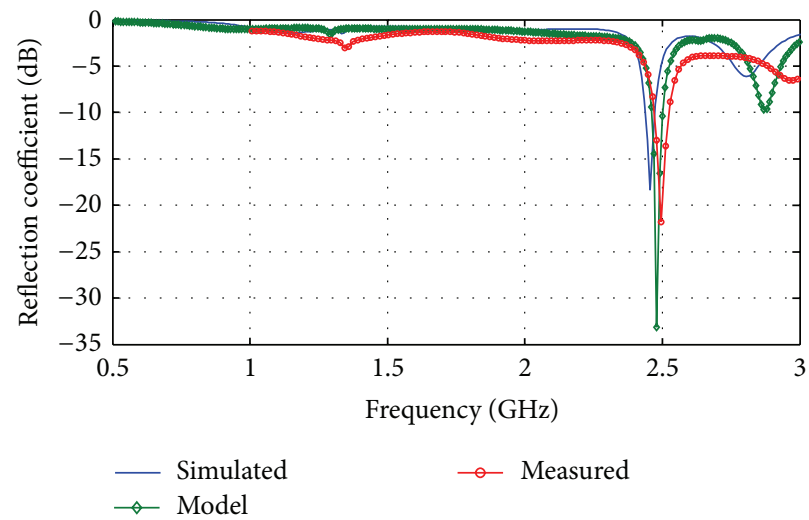

(c)

FIGURE 8: Case 1 results: comparison between input impedance and reflection coefficient of LTL analytical model, full-wave solver simulated result, and measurement result: (a) reactance, (b) resistance, and (c) reflection coefficient.

$$
\begin{aligned}
\left(\begin{array}{c}
0 \\
I_{0}^{\prime}
\end{array}\right) & =\left(\begin{array}{cc}
\cosh \gamma_{r} L_{1} & Z_{c r} \sinh \gamma_{r} L_{1} \\
\frac{1}{Z_{c r}} \sinh \gamma_{r} L_{1} & \cosh \gamma_{r} L_{1}
\end{array}\right)\left(\begin{array}{c}
V_{1} \\
I_{1}
\end{array}\right), \\
Y_{01}^{\prime}=\frac{I_{0}^{\prime}}{V_{1}} & =\frac{-\cosh ^{2} \gamma_{r} L_{1}+\sinh ^{2} \gamma_{r} L_{1}}{Z_{c r} \sinh \gamma_{r} L_{1}}=-Y_{c r} \operatorname{csch} \gamma_{r} L_{1} .
\end{aligned}
$$

Using the same method, it was found that $Y_{01}^{\prime \prime}=0$. The admittance matrix component of $Y_{01}$ is defined as $Y_{01}^{\prime}+Y_{01}^{\prime \prime}$ and expressed as

$$
Y_{01}=-Y_{c r}\left(\operatorname{csch} \gamma_{r} L_{1}\right) \text {. }
$$

3.2.3. Determining $Y_{02}$. To determine $Y_{02}$, all of the ports except port 2 are short circuited and the port voltages, $V_{n}$ for $n \neq 2$, equal zero as described in Figure 6 . Therefore,

$$
Y_{02}=0 \text {. }
$$

The other matrix component, $Y_{0 n}$, for $n=3,4, \ldots, 8$ will be equal to zero as well,

$$
Y_{02}=Y_{03}=Y_{04}=\cdots=Y_{08}=0 .
$$




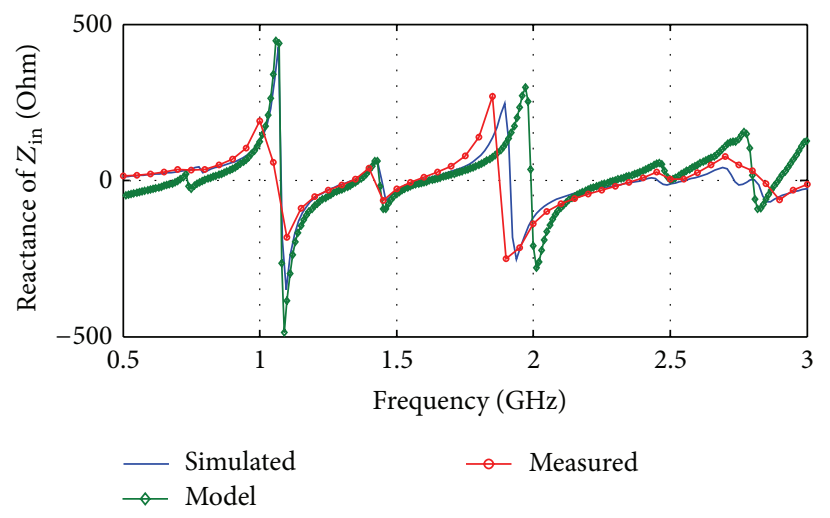

(a)

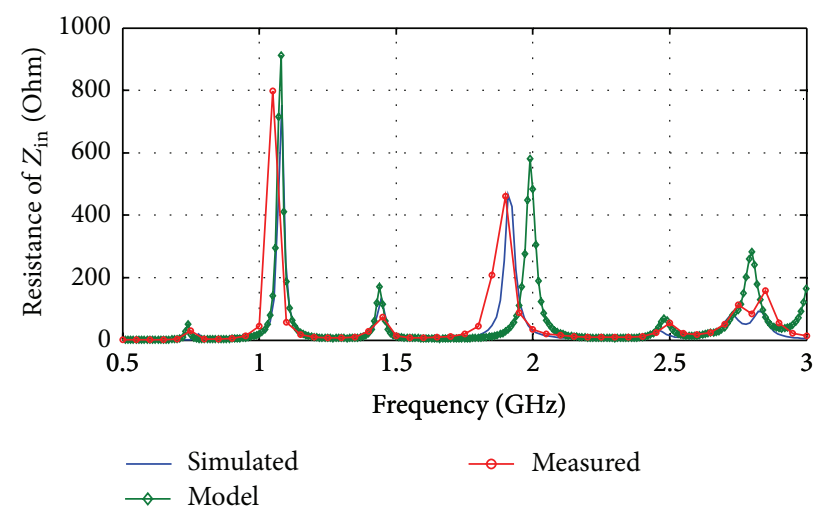

(b)

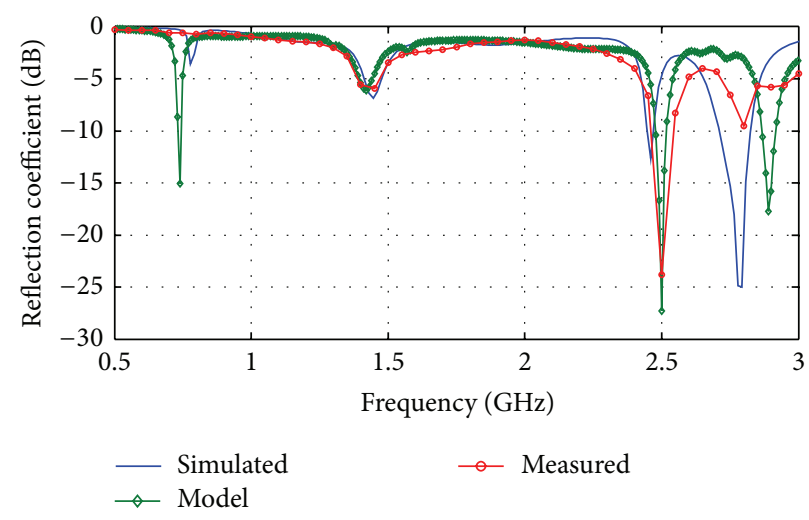

(c)

FIGURE 9: Case 2 results: comparison between input impedance and reflection coefficient of LTL analytical model, full-wave solver simulated result, and measurement result: (a) reactance, (b) resistance, and (c) reflection coefficient.

Using the same method described above, we can define all of the $Y$-admittance matrix components and they are presented in Table 1.

Transmission line parameter such as attenuation constant, $\alpha$, phase constant, $\beta$, propagation constant, $\gamma$, and characteristic admittance, $Y_{c}$, are determined using the model developed in [14].

The complete model equation for the reconfigurable antenna is defined in

$$
\left[\begin{array}{l}
I_{0} \\
I_{1} \\
I_{2} \\
I_{3} \\
I_{4} \\
I_{5} \\
I_{6} \\
I_{7} \\
I_{8} \\
I_{9}
\end{array}\right]=\left[\begin{array}{cccccccccc}
Y_{00} & Y_{00} & 0 & 0 & 0 & 0 & 0 & 0 & 0 & Y_{09} \\
Y_{10} & Y_{11} & Y_{12} & 0 & 0 & 0 & 0 & 0 & 0 & 0 \\
0 & Y_{21} & Y_{22} & Y_{23} & 0 & 0 & 0 & 0 & 0 & 0 \\
0 & 0 & Y_{32} & Y_{33} & Y_{34} & 0 & 0 & 0 & 0 & 0 \\
0 & 0 & 0 & Y_{43} & Y_{44} & Y_{45} & 0 & 0 & 0 & 0 \\
0 & 0 & 0 & 0 & Y_{54} & Y_{55} & Y_{56} & 0 & 0 & 0 \\
0 & 0 & 0 & 0 & 0 & Y_{65} & Y_{66} & Y_{67} & 0 & 0 \\
0 & 0 & 0 & 0 & 0 & 0 & Y_{76} & Y_{77} & Y_{78} & 0 \\
0 & 0 & 0 & 0 & 0 & 0 & 0 & Y_{87} & Y_{88} & Y_{89} \\
Y_{90} & 0 & 0 & 0 & 0 & 0 & 0 & 0 & Y_{98} & Y_{99}
\end{array}\right]\left[\begin{array}{c}
V_{0} \\
V_{1} \\
V_{2} \\
V_{3} \\
V_{4} \\
V_{5} \\
V_{6} \\
V_{7} \\
V_{8} \\
V_{9}
\end{array}\right]
$$

As can be seen in Figure 7, various types of discontinuities occurred in this antenna. There are bends, steps, and Tjunctions. These discontinuities were modeled by equivalent line extension.

Dearnley and Barel [15] noted that the transmission line model is also a harmonic model, so it can model the fundamental mode and its harmonics. Therefore, we combined the Dearnley model in our LTL model to create a complete model equation of the frequency reconfigurable rectangular-ring antenna.

\section{Model Validation}

In verifying the model presented above, we have calculated the input impedance and the reflection coefficient of the antenna in two different cases. Thereafter, the calculated 


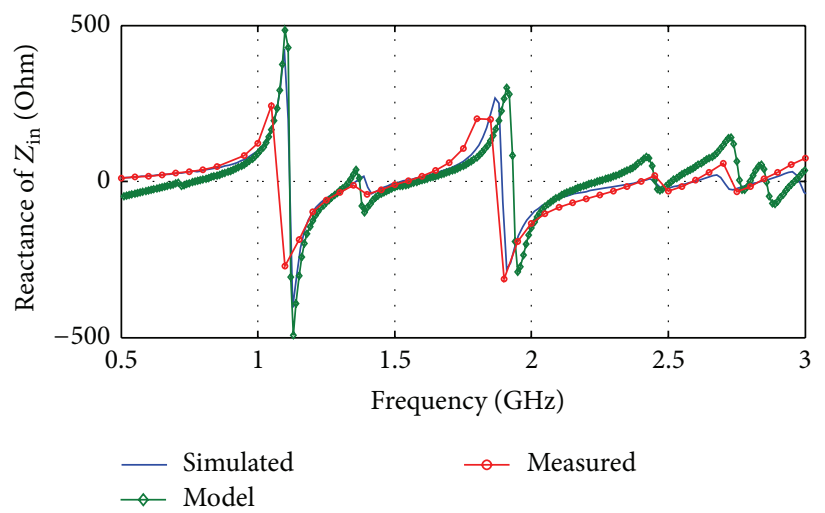

(a)

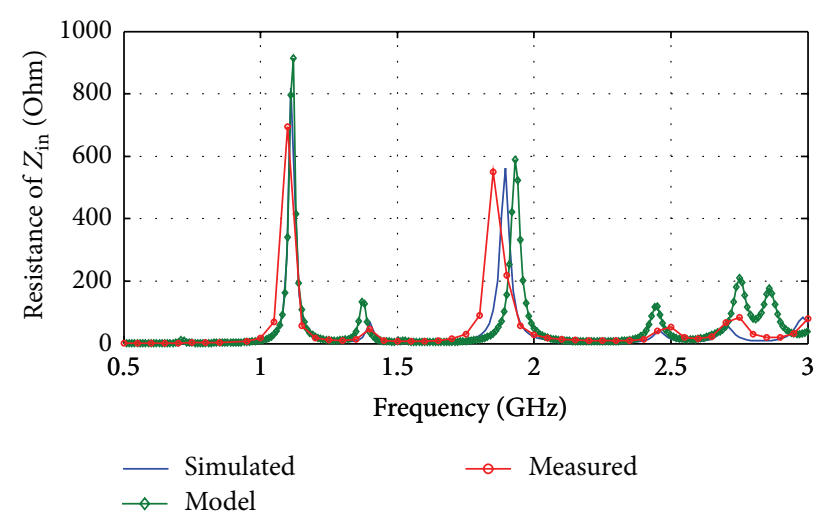

(b)

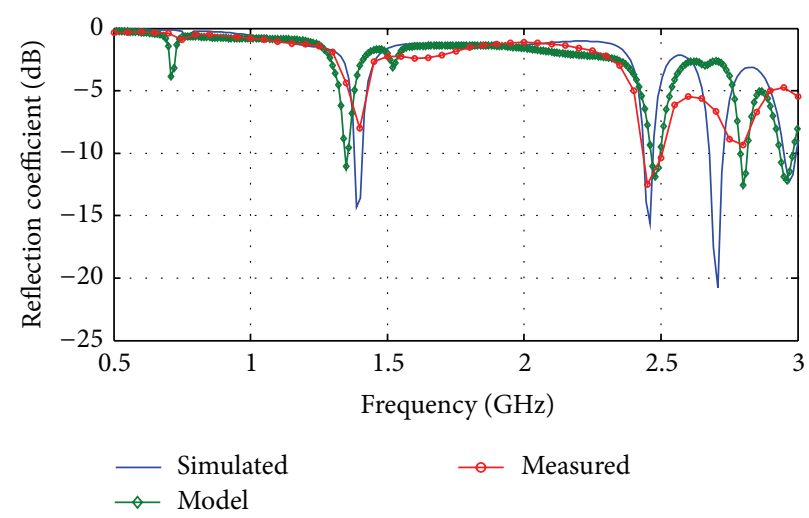

(c)

FIGURE 10: Comparison of input impedance and reflection coefficient between LTL analytical models, full-wave solver simulated results, and measurement results when $s_{9}$ is ON: (a) reactance, (b) resistance, and (c) reflection coefficient.

results are compared with the simulation and measurement results to evaluate the accuracy.

4.1. Case 1: All Switches Are OFF. When all switches are OFF, all of the loads on each port model are open circuit so that the ports current is zero,

$$
I_{n}=0 .
$$

Substituting (14) into (13), the input impedance of the rectangular-ring antenna, $Z_{A}$, can be obtained by solving the model equation using inverse matrix,

$$
\begin{gathered}
{[V]=[Y]^{-1}[I],} \\
{[Z]=[Y]^{-1},} \\
Z_{A}=\frac{V_{0}}{I_{0}}=Z_{00} .
\end{gathered}
$$

The final solution for $Z_{\text {in }}$ is obtained by substituting (17) into (4).

Results of case 1 model calculation are shown in Figure 8. In this figure, the results are compared to full-wave simulation and measurement results to show the prediction capability provided by the model. It can be seen in Figure 8 that the model agrees well with full-wave predicted input characteristics as well as measured results. This model can be used to predict the input characteristics of the reconfigurable antenna in the range of $1-3 \mathrm{GHz}$.

4.2. Case 2: One of the Switches Is ON. In this case, we examine the accuracy of the model when one of the switches is $\mathrm{ON}$, for example, $s_{1}$. When the $s_{1}$ is $\mathrm{ON}$, then the load admittance in port 1 exists, or $Y_{L 1} \neq 0$, and its current is

$$
I_{1}=Y_{L 1} V_{1} \text {. }
$$

Whereas the other ports are open circuit and the current is equal to zero,

$$
I_{n}=0, \quad \text { for } n \neq 1 \text {. }
$$

The load admittance, $Y_{L 1}$, is calculated by assuming the small patch as a microstrip line which is connected to ideal switch represented as microstrip line as well. Consider

$$
Y_{L 1}=Y_{c_{-} s w} \frac{Y_{\text {in_sp }}+Y_{c \_s w} \tanh \gamma_{\text {sw }} L_{\text {sw }}}{Y_{c_{\_} \text {sw }}+Y_{\text {in_sp }} \tanh \gamma_{\text {sw }} L_{\text {sw }}}
$$

where $Y_{c_{-} \text {sw }}$ is characteristic admittance of the ideal switch, $Y_{\text {in_sp }}$ is input admittance of small patch observed from 


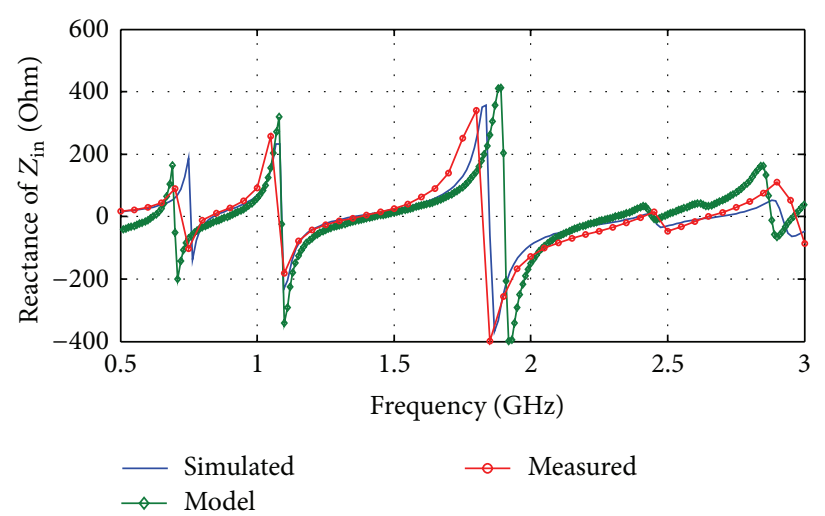

(a)

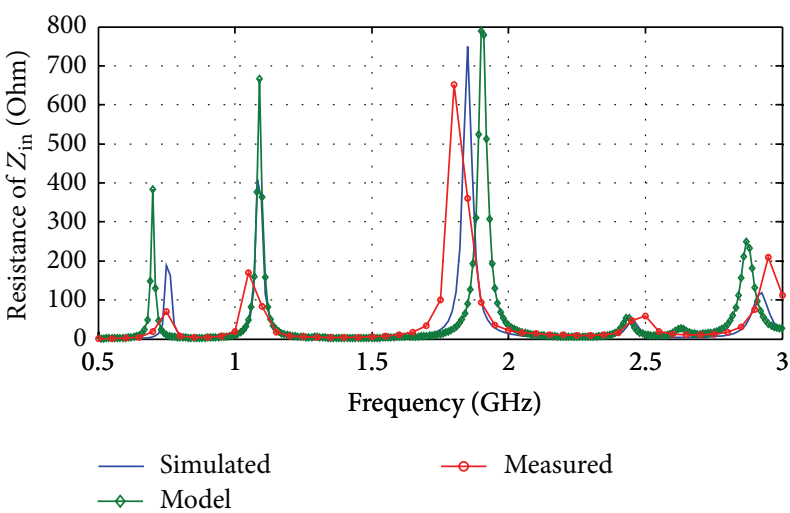

(b)

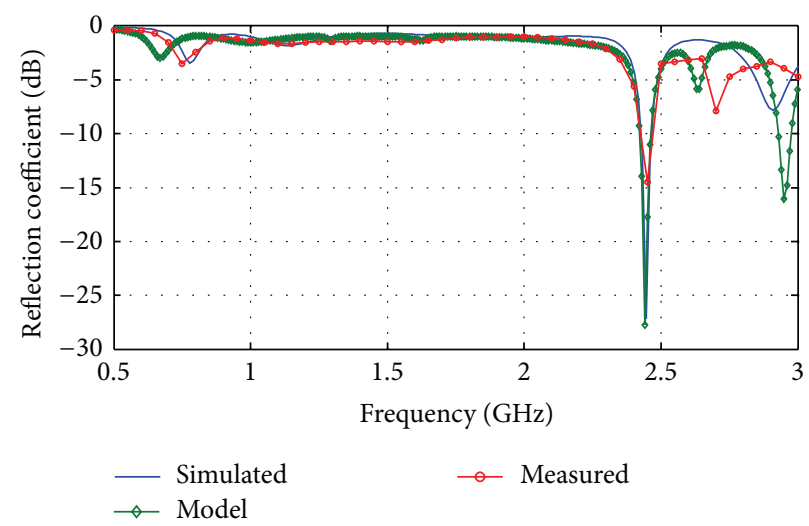

(c)

FIGURE 11: Comparison of input impedance and reflection coefficient between LTL analytical models, full-wave solver simulated results, and measurement results when $s_{7}$ is ON: (a) reactance, (b) resistance, and (c) reflection coefficient.

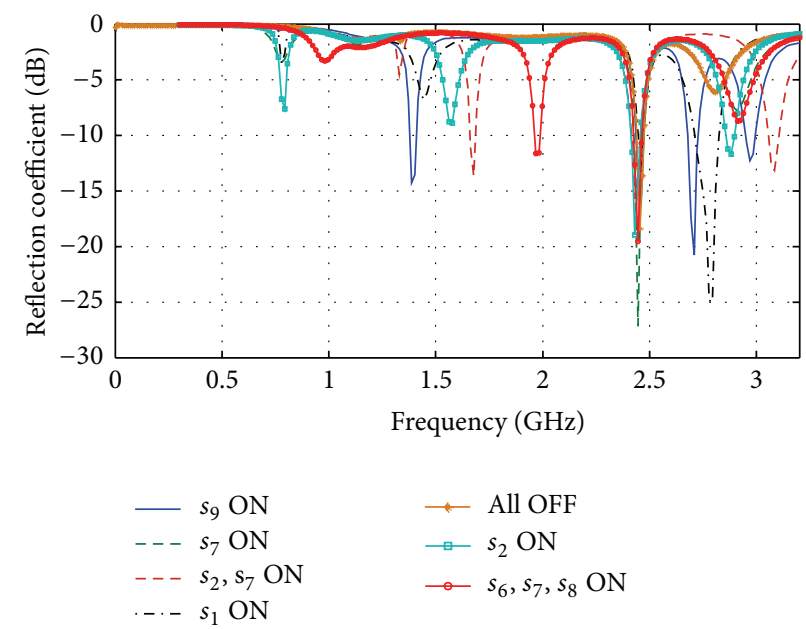

FIGURE 12: The simulation results of the antenna with several different states of switches.

the input of the ideal switch, $\gamma_{\mathrm{sw}}$ is the propagation constant of the switch, and $L_{s w}$ is the length of the switch. The input admittance of small patch, $Y_{\text {in_sp }}$, is calculated by assuming that the end of the small patch is open circuit. So, $Y_{\text {in_sp }}$ is defined as

$$
Y_{\text {in_sp }}=Y_{c_{-s p}} \tanh \gamma_{\mathrm{sp}} L_{\mathrm{sp}}
$$

Therefore, the input impedance of the rectangular-ring antenna, $Z_{A}$, is obtained by substituting (18)-(21) into (12),

$$
Z_{A}=\frac{V_{0}}{I_{0}}=Z_{00}+\frac{Z_{10} Z_{01} Y_{L 1}}{1-Z_{11} Y_{L 1}} .
$$

The final solution for $Z_{\text {in }}$ in case 2 is obtained by solving (4) which is substituted with (22). 
TABLE 1: $Y$-matrix components.

\begin{tabular}{|c|c|}
\hline$Y$-matrix component & Quantity \\
\hline$Y_{00}$ & $Y_{c r}\left(\operatorname{coth} \gamma_{r} L_{1}+\operatorname{coth} \gamma_{r} L_{10}\right)$ \\
\hline$Y_{01}$ & $-Y_{c r}\left(\operatorname{csch} \gamma_{r} L_{1}\right)$ \\
\hline$Y_{09}$ & $-Y_{c r}\left(\operatorname{csch} \gamma_{r} L_{10}\right)$ \\
\hline$Y_{10}$ & $Y_{c r}\left(\operatorname{csch} \gamma_{r} L_{1}\right)$ \\
\hline$Y_{11}$ & $-Y_{c r}\left(\operatorname{coth} \gamma_{r} L_{1}+\operatorname{coth} \gamma_{r} L_{2}\right)$ \\
\hline$Y_{12}$ & $Y_{c r}\left(\operatorname{csch} \gamma_{r} L_{2}\right)$ \\
\hline$Y_{21}$ & $Y_{c r}\left(\operatorname{csch} \gamma_{r} L_{2}\right)$ \\
\hline$Y_{22}$ & $-Y_{c r}\left(\operatorname{coth} \gamma_{r} L_{2}+\operatorname{coth} \gamma_{r} L_{3}\right)$ \\
\hline$Y_{23}$ & $Y_{c r}\left(\operatorname{csch} \gamma_{r} L_{3}\right)$ \\
\hline$Y_{32}$ & $Y_{c r}\left(\operatorname{csch} \gamma_{r} L_{3}\right)$ \\
\hline$Y_{33}$ & $-Y_{c r}\left(\operatorname{coth} \gamma_{r} L_{3}+\operatorname{coth} \gamma_{r} L_{4}\right)$ \\
\hline$Y_{34}$ & $Y_{c r}\left(\operatorname{csch} \gamma_{r} L_{4}\right)$ \\
\hline$Y_{43}$ & $Y_{c r}\left(\operatorname{csch} \gamma_{r} L_{4}\right)$ \\
\hline$Y_{44}$ & $-Y_{c r}\left(\operatorname{coth} \gamma_{r} L_{4}+\operatorname{coth} \gamma_{r} L_{5}\right)$ \\
\hline$Y_{45}$ & $Y_{c r}\left(\operatorname{csch} \gamma_{r} L_{5}\right)$ \\
\hline$Y_{54}$ & $Y_{c r}\left(\operatorname{csch} \gamma_{r} L_{5}\right)$ \\
\hline$Y_{55}$ & $-Y_{c r}\left(\operatorname{coth} \gamma_{r} L_{5}+\operatorname{coth} \gamma_{r} L_{6}\right)$ \\
\hline$Y_{56}$ & $Y_{c r}\left(\operatorname{csch} \gamma_{r} L_{6}\right)$ \\
\hline$Y_{65}$ & $Y_{c r}\left(\operatorname{csch} \gamma_{r} L_{6}\right)$ \\
\hline$Y_{66}$ & $-Y_{c r}\left(\operatorname{coth} \gamma_{r} L_{6}+\operatorname{coth} \gamma_{r} L_{7}\right)$ \\
\hline$Y_{67}$ & $Y_{c r}\left(\operatorname{csch} \gamma_{r} L_{7}\right)$ \\
\hline$Y_{76}$ & $Y_{c r}\left(\operatorname{csch} \gamma_{r} L_{7}\right)$ \\
\hline$Y_{77}$ & $-Y_{c r}\left(\operatorname{coth} \gamma_{r} L_{7}+\operatorname{coth} \gamma_{r} L_{8}\right)$ \\
\hline$Y_{78}$ & $Y_{c r}\left(\operatorname{csch} \gamma_{r} L_{8}\right)$ \\
\hline$Y_{87}$ & $Y_{c r}\left(\operatorname{csch} \gamma_{r} L_{8}\right)$ \\
\hline$Y_{88}$ & $-Y_{c r}\left(\operatorname{coth} \gamma_{r} L_{8}+\operatorname{coth} \gamma_{r} L_{9}\right)$ \\
\hline$Y_{89}$ & $Y_{c r}\left(\operatorname{csch} \gamma_{r} L_{9}\right)$ \\
\hline$Y_{98}$ & $Y_{c r}\left(\operatorname{csch} \gamma_{r} L_{9}\right)$ \\
\hline$Y_{99}$ & $-Y_{c r}\left(\operatorname{coth} \gamma_{r} L_{9}+\operatorname{coth} \gamma_{r} L_{1}\right)$ \\
\hline$Y_{90}$ & $Y_{c r}\left(\operatorname{csch} \gamma_{r} L_{1}\right)$ \\
\hline Remaining components & 0 \\
\hline
\end{tabular}

After calculating all of the possible modes, results of this analytical model are compared to the full wave simulation and measurement results, as seen in Figure 9. In this figure, the model shows a good agreement with the simulated and measured results and it can be used to predict the resonant frequency of the reconfigurable antenna.

To show the generality of the model, we present the other examples of the proposed model calculation results for the other ON switch configurations. The model calculation results when $s_{9}$ is $\mathrm{ON}$ and $s_{7}$ is $\mathrm{ON}$ are depicted in Figures 10 and 11, respectively. The results agree well with simulated and measured results.

In Figure 12, we present the simulation results of the reconfigurable antenna with several different states of the switches. It can be seen that the reconfiguration of the antenna frequency can be achieved by changing the position and the number of the switches.

\section{Conclusion}

We presented modeling of a frequency reconfigurable rectangular-ring microstrip antenna using lossy-transmission-line and multiport network model. The model can be used to analytically derive the input characteristic of the reconfigurable antenna with arbitrary number of switches. The results show good accuracy and agreement in a wide range of frequency for single ON-switch configuration. Furthermore, this analytical model can be used to predict the appropriate switch locations in generating the desired operating frequency.

\section{Conflict of Interests}

The authors declare that there is no conflict of interests regarding the publication of this paper.

\section{References}

[1] J. T. Bernhard, Reconfigurable Antennas, chapter 4, section 4.2, Morgan \& Claypool, 2007.

[2] L. Pazin and Y. Leviatan, "Reconfigurable slot antenna for switchable multiband operation in a wide frequency range," IEEE Antennas and Wireless Propagation Letters, vol. 12, pp. 329-332, 2013.

[3] H. F. Abutarboush, R. Nilavalan, S. W. Cheung et al., "A reconfigurable wideband and multiband antenna using dualpatch elements for compact wireless devices," IEEE Transactions on Antennas and Propagation, vol. 60, no. 1, pp. 36-43, 2012.

[4] D. Peroulis, K. Sarabandi, and L. P. B. Katehi, "Design of reconfigurable slot antennas," IEEE Transactions on Antennas and Propagation, vol. 53, no. 2, pp. 645-654, 2005.

[5] C. Zhang, S. Yang, S. El-Ghazaly, A. E. Fathy, and V. K. Nair, "A low-profile branched monopole laptop reconfigurable multiband antenna for wireless applications," IEEE Antennas and Wireless Propagation Letters, vol. 8, pp. 216-219, 2009.

[6] R. Gonçalves, P. Pinho, and N. B. Carvalho, "Compact, frequency reconfigurable, printed monopole antenna," International Journal of Antennas and Propagation, vol. 2012, Article ID 602780, 6 pages, 2012.

[7] J.-F. Tsai and J.-S. Row, "Reconfigurable square-ring microstrip antenna," IEEE Transactions on Antennas and Propagation, vol. 61, no. 5, pp. 2857-2860, 2013.

[8] Y. J. Sung, "Frequency and polarisation reconfigurability from an open-loop square ring antenna," IET Microwaves, Antennas and Propagation, vol. 6, no. 5, pp. 505-509, 2012.

[9] M. A. Alkanhal and A. F. Sheta, "A novel dual-band reconfigurable square-ring microstrip antenna," Progress in Electromagnetics Research, vol. 70, pp. 337-349, 2007.

[10] B. S. Nugroho, F. Y. Zulkifli, and E. T. Rahardjo, "Simple frequency reconfigurable antenna by changing the number and position of the switches," in Proceedings of the 12th International Conference on Quality in Research (QiR '11), pp. 428-433, Bali, Indonesia, 2011.

[11] B. S. Nugroho, F. Y. Zulkifli, and E. T. Rahardjo, "PIN diodes slotted microstrip antenna as frequency reconfigurable antenna," in Proceedings of the 17th International Symposium on Antennas and Propagation, pp. 814-817, Nagoya, Japan, November 2012. 
[12] E. T. Rahardjo, F. Y. Zulkifli, and B. S. Nugroho, "Multiband reconfigurable microstrip antenna," in Proceedings of the Asia Pacific Conference on Antennas and Propagation, Chiang Mai, Thailand, 2013.

[13] R. Garg and V. S. Reddy, "Edge feeding of microstrip ring antennas," IEEE Transactions on Antennas and Propagation, vol. 51, no. 8, pp. 1941-1946, 2003.

[14] D. M. Pozar, Microwave Engineering, chapter 3, sec. 3.8, John Wiley \& Sons, New York, NY, USA, 3rd edition, 2005.

[15] R. W. Dearnley and A. R. F. Barel, "Broad-band transmission line model for a rectangular microstrip antenna," IEEE Transactions on Antennas and Propagation, vol. 37, no. 1, pp. 6-15, 1989. 

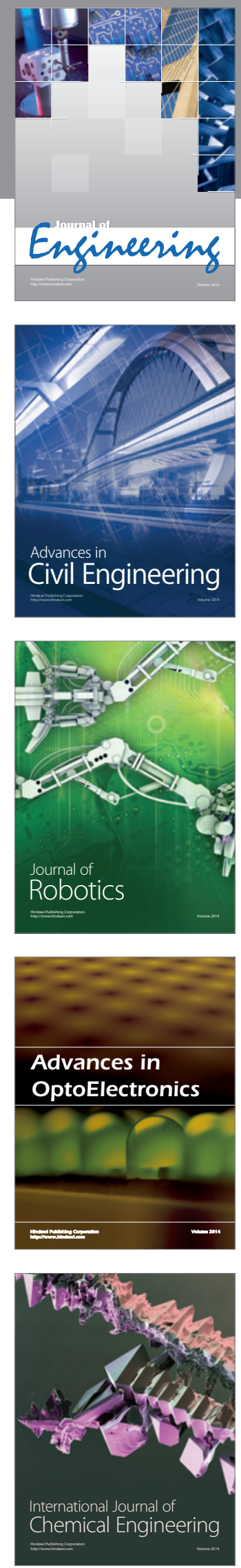

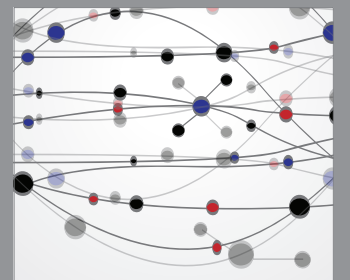

The Scientific World Journal
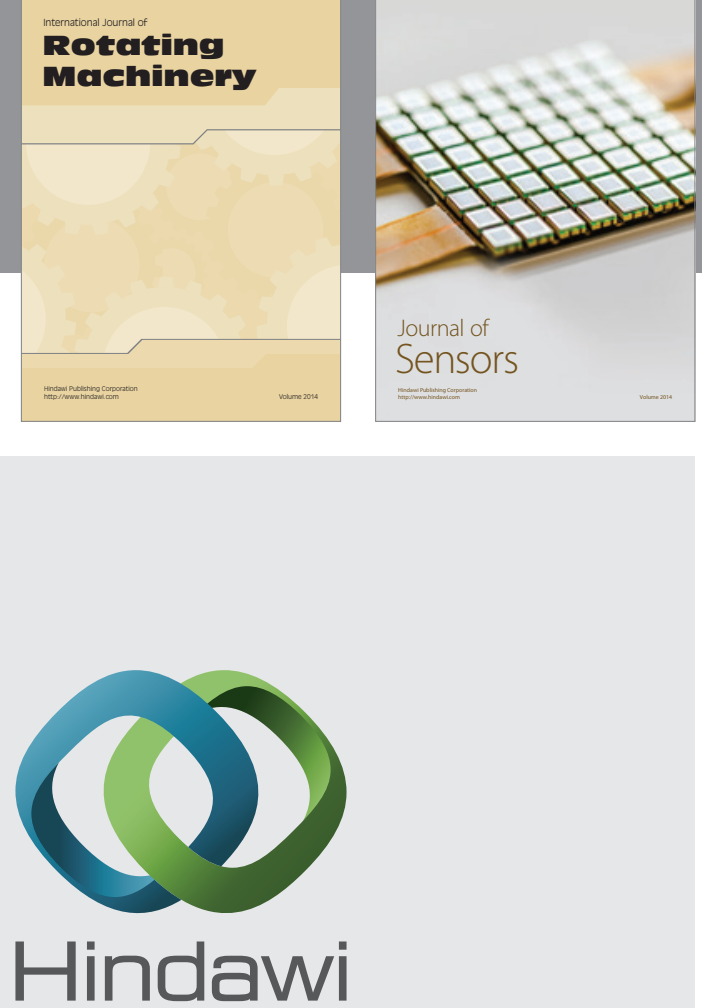

Submit your manuscripts at http://www.hindawi.com
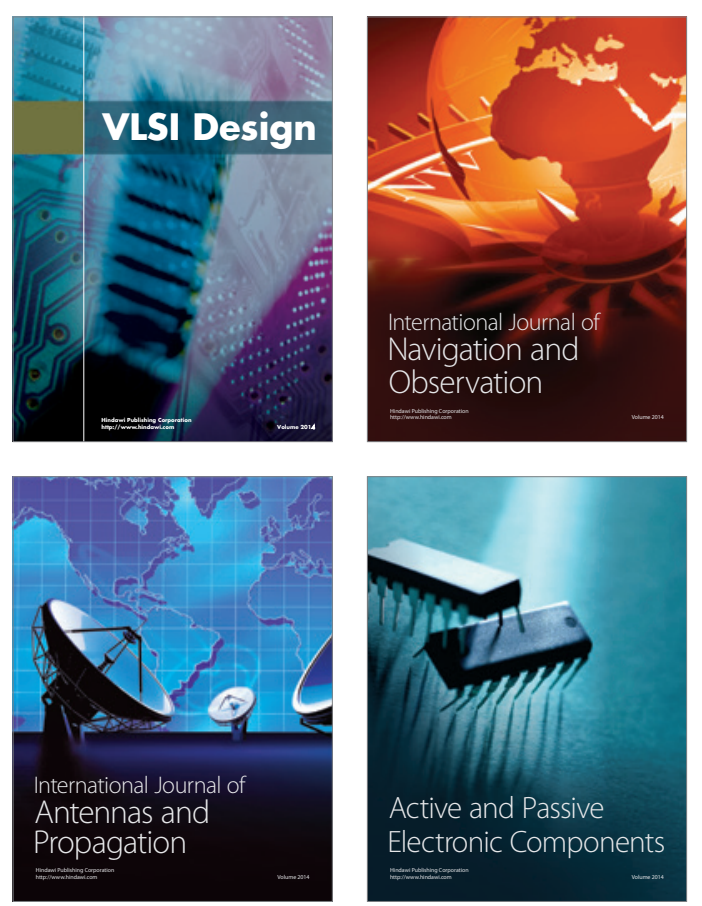
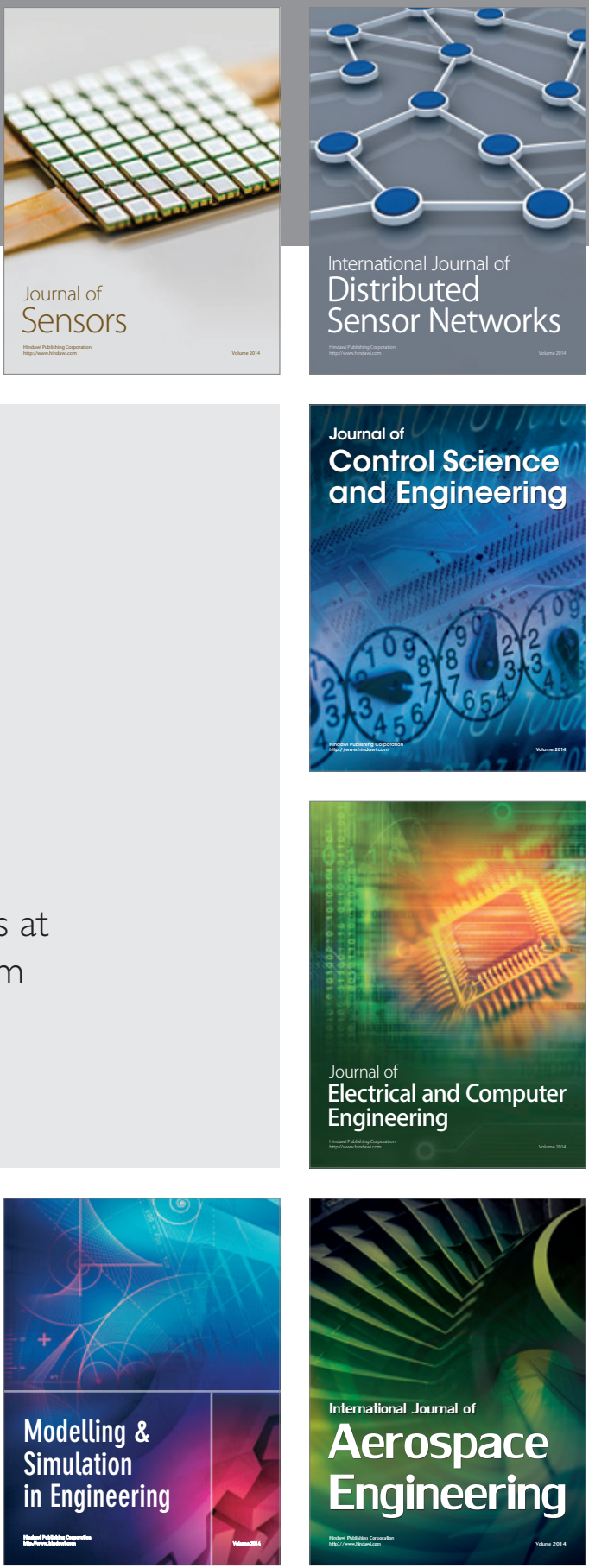

Journal of

Control Science

and Engineering
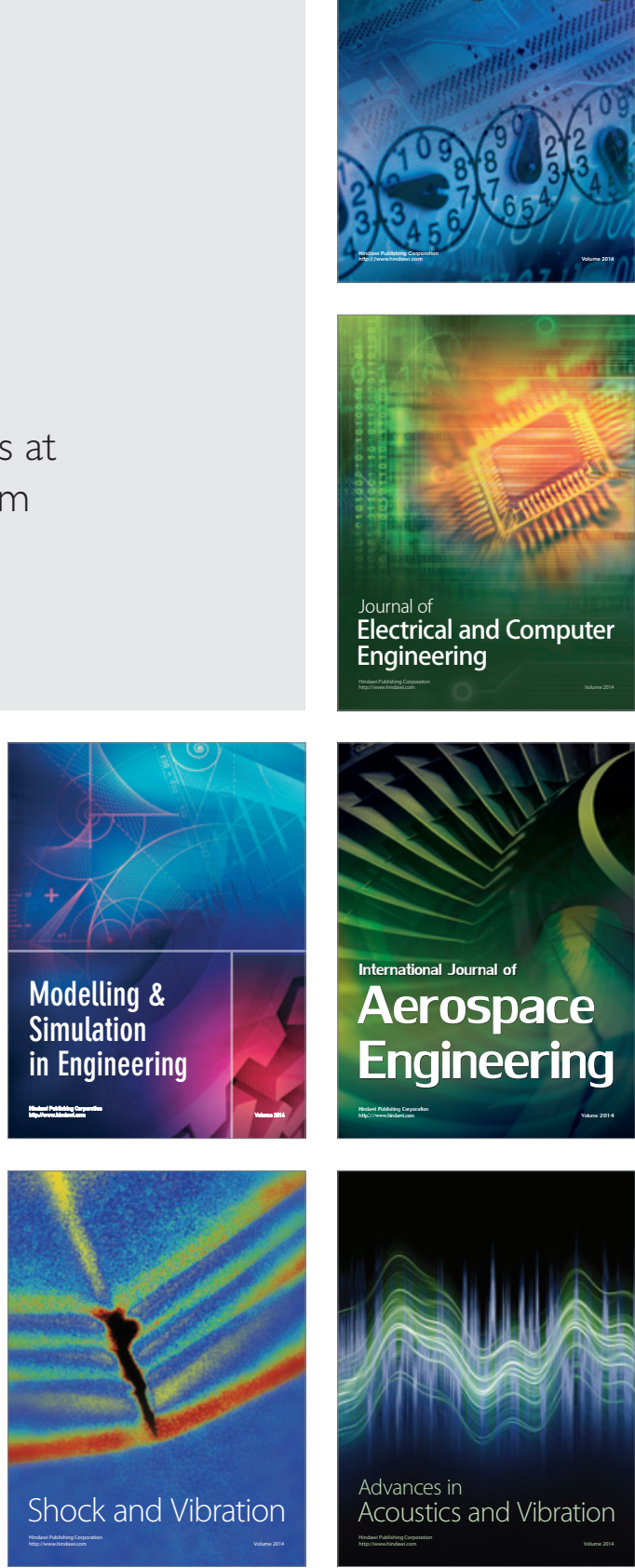